Arq. Bras. Med. Vet. Zootec., v.66, n.3, p.778-786, 2014

\title{
Time-domain signal-averaged electrocardiogram in healthy German Shepherd and Boxer dogs
}

[Eletrocardiograma de alta resolução (ECGAR) no domínio do tempo em cães sadios das raças Pastor Alemão e Boxer]

P.P.C. Chamas, V.M.C. Oliveira, F.L. Yamaki, M.H.M.A. Larsson

Faculdade de Medicina Veterinária - Universidade de São Paulo - USP - São Paulo, SP

\begin{abstract}
Signal-averaged electrocardiogram (SAECG) identifies ventricular late potentials (LP), low-amplitude electrical signals that are markers of slow cardiac conduction in fibrous myocardium, consisting in a predictive factor for sudden death in dogs at risk of sustained ventricular tachycardia. The aim of this study was to establish reference values of SAECG for German Shepherd and Boxer dogs. SAECG was performed in 19 German Shepherd and 28 Boxer client-owned dogs, and parameters analyzed were QRSd (duration of filtered QRS), LAS $\angle 40 \mu \mathrm{V}$ (duration of low-amplitude signals in terminal portion of filtered QRS) and RMS40 (root square of mean voltage over the last 40 milliseconds of filtered QRS), with two different filters $(25-250 \mathrm{~Hz}$ and $40-250 \mathrm{~Hz})$. Statistical analyses was achieved by T Student test $(\mathrm{p}<0.05)$ to identify differences between the two groups and between the values obtained with the two filters. No statistical difference was found in SAECG variables between the two breeds with the two different filters ( $p>0.05)$. Achieving normal values of SAECG in German Shepherd and Boxer dogs is important to further research late potentials in animals of these breeds with hereditary ventricular tachycardia or arrhythmogenic cardiomyopathy and identification of individuals at high risk of cardiac-related sudden death.
\end{abstract}

Keywords: canine, high-resolution electrocardiography, ventricular tachycardia, arrhythmogenic right ventricular cardiomyopathy

\section{RESUMO}

O eletrocardiograma de alta resolução (ECGAR) identifica os potenciais tardios (PT), sinais elétricos de baixa amplitude considerados marcadores de condução cardíaca lenta de áreas fibrosadas do miocárdio, cuja presença consiste em fator preditivo de morte súbita em cães com taquicardia ventricular sustentada. O objetivo deste estudo foi o estabelecimento de valores de referência para o ECGAR de cães Boxer $(n=28)$ e Pastor Alemão $(n=19)$. Os seguintes parâmetros do ECGAR foram analisados: dQRS (duração do QRS filtrado), LAS $<40 \mu \mathrm{V}$ (duração dos sinais de baixa amplitude no final do QRS filtrado) e RMS40 (raiz quadrada da voltagem média do final do QRS filtrado), com dois tipos diferentes de filtro (25-250 Hz e 40-250 Hz). Análise estatística foi realizada por meio do teste T de Student $(p<0,05)$ para identificar diferenças entre os dois grupos e entre os valores obtidos com os dois filtros. Não foram encontradas diferenças significativas entre as variáveis de ECGAR nas duas raças estudadas com os dois diferentes filtros $(p>0,05)$. A obtenção dos valores de normalidade de ECGAR em cães dessas raças auxiliará na realização de futuras pesquisas de potenciais tardios em animais com taquicardia ventricular hereditária ou cardiomiopatia arritmogênica, bem como na identificação dos indivíduos com alto risco de morte súbita de origem cardíaca.

Palavras-chave: cão, eletrocardiograma de alta resolução, taquicardia ventricular, cardiomiopatia arritmogênica do ventrículo direito

Recebido em 4 de setembro de 2012

Aceito em 20 de dezembro de 2013

E-mail: pchamas@yahoo.com.br 


\section{INTRODUCTION}

Time-domain signal-averaged electrocardiogram (SAECG) is an easily applied, noninvasive diagnostic technique that detects the presence of late potentials (LP), high-frequency and low-amplitude signals that occur at the end of the QRS complex. Late potentials are not detected by conventional ECG because of their low amplitude and due to masking by noise produced during respiratory movements and muscle tremors. By using high-gain amplification of up to 100 times and by increasing the speed of signal acquisition, the LP can easily be recorded. These signals are considered markers of slow and heterogeneous cardiac conduction between myocardial cells interspersed with fibrous tissue, which provides a substrate for the appearance and maintenance of ventricular tachycardia by a re-entry mechanism. Therefore, the identification of LP can be used as a predictor of risk for future arrhythmic events and sudden cardiac death (Breithardt et al., 1991; Leclercq, Coumel, 1993; Calvert, 1998; Spier, Meurs, 2004b; Bernadic et al., 2005).

In humans, besides being used to identify patients at risk of developing ventricular tachycardia (VT) and sudden death after myocardial infarction, the SAECG is also performed to identify LP prior to electrophysiological study in patients with nonsustained VT, as well as in patients with a history of syncope, Duchenne muscular dystrophy (Corrado et al., 2002), ventricular aneurysms, tachycardia and ventricular fibrillation, arrhythmogenic right ventricular cardiomyopathy (ARVC), and nonischemic congestive cardiomyopathies (Poll et al., 1985; Kinoshita et al., 1995).

Although there are few studies that establish reference values for SAECG in healthy dogs (Calvert, 1998; Spier, Meurs, 2004b; Bernadic et al., 2005; Kushner et al., 1996; Calvert et al., 1998a), there is great interest in its use, particularly for identification of LP in Doberman and Boxer dogs with occult or pre-congestive cardiomyopathy, which are susceptible to developing VT and sudden death (Calvert, 1998). Also, SAECG should be performed to evaluate the risk of sudden cardiac death in all patients that showed ventricular tachycardia on Holter or conventional electrocardiogram evaluation (Breithardt et al., 1991; Calvert, 1998).
The performance of SAECG in Doberman dogs with dilated cardiomyopathy showed a good correlation between the presence of LP and occurrence of sudden death, although such deaths also occurred in animals with normal SAECG results (Calvert et al., 1998a). The detection of LP in the SAECG of Boxer dogs with ARVC was associated with high sensitivity and specificity in predicting cardiac-related deaths (sudden death or congestive heart failure) in those animals (Spier, Meurs, 2004b).

The purpose of the present study was to establish normal values of the signal-averaged electrocardiogram (SAECG) in clinically healthy German Shepherd and Boxer dogs. The values determined now can be compared in the future with those obtained from animals with familial ventricular arrhythmia and with dilated or arrhythmogenic cardiomyopathy. These comparisons can provide a means to identify the presence of LP in SAECG for use as prognostic indicators for these myocardial diseases.

\section{MATERIAL AND METHODS}

Forty-seven apparently healthy dogs were used, where 19 were German Shepherds and 28 were Boxer dogs of both genders, with ages ranging from 2 to 10 years. The selection of these breeds was based on the applicability of this examination, since animals of these breeds are prone to developing ventricular arrhythmias that may be associated with presence of LP in SAECG. The animals of the German Shepherd and Boxer dog groups were also grouped according to age ( 1 to 4 years, $>4$ to $<8$ years and $>8$ years) to determine the influence of age on the parameters of SAECG.

The animals were evaluated by physical examination, laboratory survey, blood pressure measurement, chest radiography, conventional electrocardiogram, Doppler echocardiography and 24-hour ambulatory electrocardiographic monitoring (Holter). The presence of right or left bundle branch block detected by electrocardiogram was considered an exclusion factor because the identification of LP may be masked by pre-existing conduction defects that generate wide QRS complexes (Turrini et al., 1999; Spier, Meurs, 2004a). Animals with changes suggestive of cardiac disease or 
systemic diseases with an impact on the cardiovascular system were also excluded.

The selected animals were submitted to the SAECG with a digital Holter recorder (DMS 300-7). For the SAECG, the electrodes were attached to the skin after prior trichotomy and degreasing with alcohol and were positioned creating a system of orthogonal leads as described by Calvert (1998): X lead (electrodes in the right and left fifth or sixth intercostal spaces), Y lead (electrodes on the manubrium and xiphoid cartilage) and $\mathrm{Z}$ lead (electrode on the seventh thoracic vertebra and on the sternum in its opposite side) (Figure 1). The examination was carried out without sedation, with the animal acclimated in a silent and restful setting; when the animals were restless they were calmed down only by doctor-patient and owner interaction. We chose to perform SAECG without sedation due to resistance offered by owners to this procedure. This led to exclusion of several tracings that interfered with the base line, caused by restlessness and muscle tremors in some animals. Unacceptable SAECG records, with high noise level or excessive interference were repeated one or two times until a suitable tracing was achieved, or the dog was dropped from the study when no examination provided appropriated tracing. To perform SAECG the dogs were placed in right lateral recumbence on a rubber mat for a period of 40 to 60 minutes; this side of recumbence was chosen based on previous studies of SAECG performed in dogs, so that we could compare our results with those previously described by other authors (Kushner et al., 1996; Spier et al., 2001).

The exams that had less than 200 cardiac cycles were excluded. The data recorded on the card were analyzed by computerized decoding (CardioScan 10 and 12 - DMS/Brazil), and the selected QRS complexes were added, amplified (100 times for voltage at $100 \mathrm{~mm} / \mathrm{s}$ ) and filtered with bidirectional filters $(25$ to $250 \mathrm{~Hz}$ and 40 to $250 \mathrm{~Hz}$ ), thus generating a filtered QRS free of low-frequency electrical signals (Figure 2). The following parameters were analyzed: QRSd (milliseconds) $=$ width of filtered QRS, which increases in the presence of LP; LAS $<40 \mu \mathrm{V}$ (milliseconds) $=$ duration of the high-frequency and low-amplitude signals (less than 40 microvolts) in the terminal portion of the filtered QRS complex, which increases in the presence of
LP; and RMS40 (microvolts) = root square of mean voltage over the last 40 milliseconds of the filtered QRS, which value is inversely proportional to the LP degree. Alterations in at least two of these three reported parameters were considered suggestive of LP presence.

Statistical analysis of the mean values of QRSd, LAS $\angle 40 \mu \mathrm{V}$ and RMS40 for dogs of both breeds and with the two filters (25 to $250 \mathrm{~Hz}$ and 40 to $250 \mathrm{~Hz}$ ) was performed using the unpaired Student's t-test with a confidence interval of $95 \%$ (significance was defined as $\mathrm{p}<0.05$ ), after application of the Kolmogorov-Smirnov test that indicated normal distribution of these variables. Also, in order to evaluate statistical differences regarding the age of the animals, Student's t-test was applied to the German Shepherd group who had two subgroups ( 1 to 4 years and $>4$ years) and ANOVA was used in the Boxer group, who had three subgroups ( 1 to 4 years, $>4$ to $<8$ years and $>8$ years) .

The present research agreed with the Ethical Principles in Animal Research adopted by the Bioethic Comission of the Faculty of Veterinary Medicine and Zootechny of the University of São Paulo.

\section{RESULTS}

The mean, standard deviation and minimum and maximum values of QRSd (ms), LAS $<40 \mu \mathrm{V}$ (ms) and RMS40 ( $\mu \mathrm{v})$ of the SAECG of German Shepherd and Boxer dogs obtained with two different types of filter are presented, respectively, in Tables 1-3.

No statistical significant differences between the means of these three mentioned parameters were observed in either breed studied ( $p>0.05)$, even after comparing the values obtained with the two different types of filter used (25 to $250 \mathrm{~Hz}$ and 40 to $250 \mathrm{~Hz}$ ). However, separately analyzing the animals grouped according to age, we noted that using the filter 25 to $250 \mathrm{~Hz}$ there was, in the German Shepherd dog group, statistically significant difference between the values of QRSd ( $\mathrm{p}=0.048)$, LAS ( $\mathrm{p}=0.0023)$ and RMS $(\mathrm{p}=0.001)$ obtained for dogs up to 4 years and dogs over 4 years, while for the Boxer dog group only LAS $(p=0.0145)$ differed among the age groups. Using the filter 40 to $250 \mathrm{~Hz}$, these differences were not observed. 


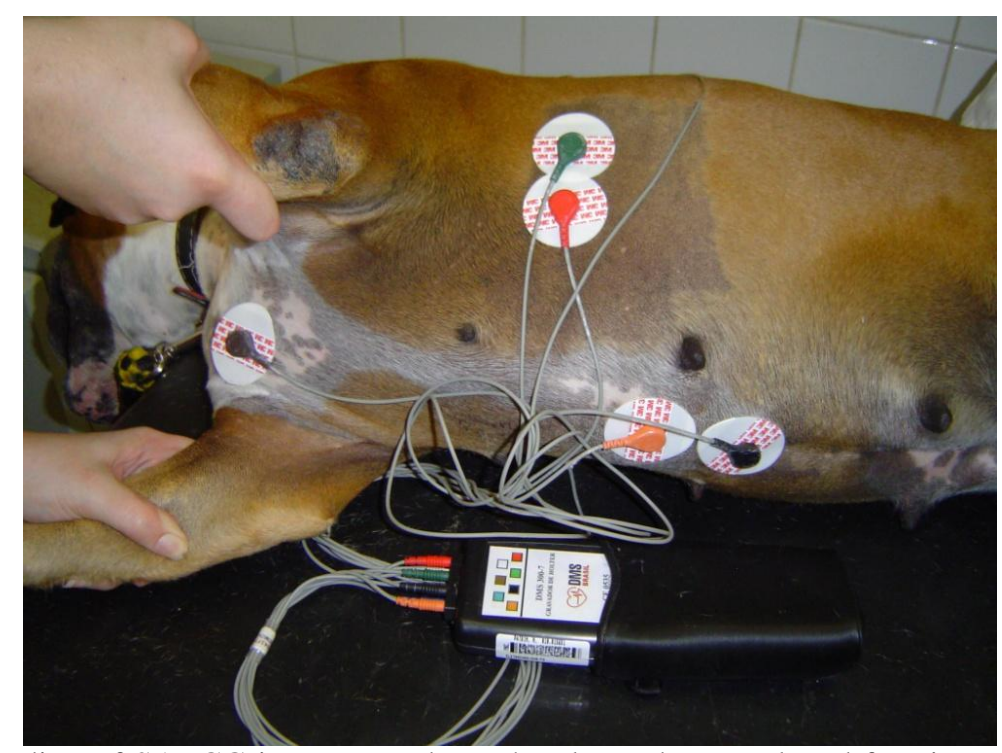

Figure 1. Recording of SAECG in a Boxer dog. The electrodes are placed forming an orthogonal lead system (leads $\mathrm{X}, \mathrm{Y}$ and Z).
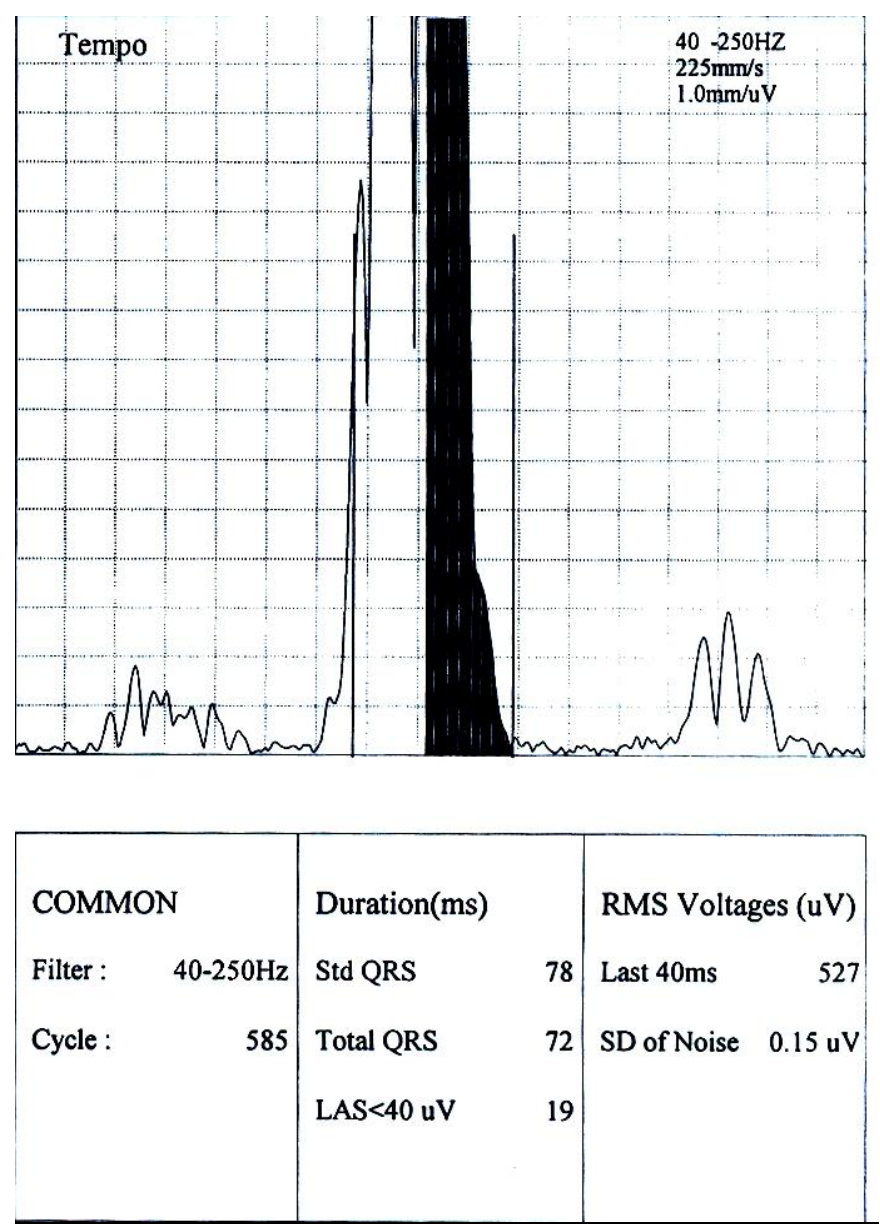

Figure 2. Graphic representation of the filtered QRS obtained in the SAECG of a German Shepherd dog, showing QRSd (Total QRS), LAS $<40 \mu \mathrm{v}$ and RMS40 values. 
Table 1. QRSd values obtained in the SAECG of healthy German Shepherd and Boxer dogs. São Paulo, 2012

\begin{tabular}{ccccc}
\hline $\begin{array}{c}\text { QRSd (ms) - 40 - 250 } \\
\text { Hz Filter }\end{array}$ & Mean \pm SD & Median & $\begin{array}{c}\text { Minimum } \\
\text { value }\end{array}$ & $\begin{array}{c}\text { Maximum } \\
\text { value }\end{array}$ \\
\hline $\begin{array}{c}\text { German Shepherd } \\
\text { Boxer }\end{array}$ & $76.11 \pm 5.55 \mathrm{a}$ & 77.0 & 68.0 & 86.0 \\
\hline QRSd (ms) - 25 - & Mean \pm SD & Median & Minimum value & $\begin{array}{c}\text { Maximum } \\
\text { value }\end{array}$ \\
250-Hz Filter & & & & 96.0 \\
\hline $\begin{array}{c}\text { German Shepherd } \\
\text { Boxer }\end{array}$ & $82.16 \pm 5.85 \mathrm{a}$ & 83.0 & 70.0 & 92.0 \\
\hline
\end{tabular}

Values followed by the same letters in the column do not differ by Student's t-test ( $p>0.05$ ).

Table 2. LAS $<40 \mu$ v values obtained in the SAECG of healthy German Shepherd and Boxer dogs. São Paulo, 2012

\begin{tabular}{ccccc}
\hline $\begin{array}{c}\text { LAS }<40 \mu \mathrm{v}(\mathrm{ms}) 40 \\
-250-\mathrm{Hz} \text { Filter }\end{array}$ & Mean $\pm \mathrm{SD}$ & Median & $\begin{array}{c}\text { Minimum } \\
\text { value }\end{array}$ & $\begin{array}{c}\text { Maximum } \\
\text { value }\end{array}$ \\
\hline $\begin{array}{c}\text { German Shepherd } \\
\text { Boxer }\end{array}$ & $21.11 \pm 2.85 \mathrm{a}$ & 22.0 & 15.0 & 26.0 \\
\hline LAS $<40 \mu \mathrm{v}(\mathrm{ms}) 25$ & Mean $\pm \mathrm{SD}$ & Median & Minimum value & $\begin{array}{c}\text { Maximum } \\
\text { value }\end{array}$ \\
$-250-\mathrm{Hz}$ Filter & & & & 33.0 \\
\hline $\begin{array}{c}\text { German Shepherd } \\
\text { Boxer }\end{array}$ & $24.84 \pm 5.67 \mathrm{a}$ & 25.0 & 13.0 & 36.0 \\
\hline
\end{tabular}

Values followed by the same letters in the column do not differ by Student's t-test ( $p>0.05)$.

Table 3. RMS40 values obtained in the SAECG of healthy German Shepherd and Boxer dogs. São Paulo, 2012

\begin{tabular}{|c|c|c|c|c|}
\hline $\begin{array}{l}\text { RMS } 40(\mu \mathrm{v}) 40 \text { - } \\
250 \mathrm{~Hz} \text {-Filter }\end{array}$ & Mean \pm SD & Median & $\begin{array}{l}\text { Minimum } \\
\text { value }\end{array}$ & $\begin{array}{l}\text { Maximum } \\
\text { value }\end{array}$ \\
\hline German Shepherd & $374.68 \pm 161.02 \mathrm{a}$ & 351.0 & 125.0 & 829.0 \\
\hline Boxer & $384.89 \pm 206.60 \mathrm{a}$ & 334.5 & 120.0 & 808.0 \\
\hline $\begin{array}{l}\text { RMS } 40 \text { ( } \mu \mathrm{v}) 25 \text { - } \\
250 \text { Hz-Filter }\end{array}$ & Mean \pm SD & Median & $\begin{array}{l}\text { Minimum } \\
\text { value }\end{array}$ & $\begin{array}{l}\text { Maximum } \\
\text { value }\end{array}$ \\
\hline German Shepherd & $473.58 \pm 268.88 \mathrm{a}$ & 574.0 & 157.0 & 880.0 \\
\hline Boxer & $448.43 \pm 230.85 a$ & 452.0 & 109.0 & 991.0 \\
\hline
\end{tabular}

Values followed by the same letters in the column do not differ by Student's t-test ( $p>0.05$ ).

\section{DISCUSSION}

Despite the importance of predicting sudden death in dogs suffering from diseases that lead to VT, there are few studies establishing reference values of SAECG in dogs and the results of this examination may be used as prognostic factors in these diseases.

Because of the diversity in technical specifications of commercially available systems for interpretation of SAECG, some authors point out the need to standardize the performance and interpretation of this test, so results from several studies can be compared (Breithardt et al., 1991; Bernadic et al., 2005). Differences in methodology, such as the type of filter used, positioning of the animal, location of electrodes to form the orthogonal derivations system and analysis of different parameters of the filtered QRS complex, make it difficult to compare data obtained in this study with those presented in literature.

The characteristics of the high-frequency bandpass filter are crucial in signal-averaged electrocardiography in the time domain, as they determine the configuration and amplitude of the signals to be analyzed. Although there is controversy regarding the optimal filter to be used, bidirectional 25 to $250 \mathrm{~Hz}$ or 40 to $250 \mathrm{~Hz}$ filters are used most frequently (Breithardt et al., 1991). Some studies in humans, however, also 
use the 80 to $250 \mathrm{~Hz}$ filter and often compare the SAECG results obtained with these three types of filters (Turrini et al., 1999; Folino et al., 2006; Steriotis et al., 2009). In dogs, most SAECG studies are performed using only the 40 to 250 Hz filter (Kushner et al., 1996; Calvert et al., 1998a; Calvert et al., 1998b; Ferreira, Camacho, 2005). Despite this convention, in the present study, we chose to use two filters, 25 to $250 \mathrm{~Hz}$ and 40 to $250 \mathrm{~Hz}$, similar to some previous SAECG studies performed on Boxer dogs (Kushner et al., 1996; Spier et al., 2001). Analyzing the entire sample of animals used in this study, there was no significant difference in the mean values of the parameters studied using either filters; however, statistical analyzes revealed significant difference between values of QRSd, LAS and RMS obtained with the 25 to $250 \mathrm{~Hz}$ filter when the German Shepherd dogs were separated by different age groups, which was similar only with the LAS of the Boxer dog group. This can be explained by the type of filter used, since the 25 to $250 \mathrm{~Hz}$ band-pass filter may have allowed more low amplitude and high frequency signals to pass (thus increasing the QRSd and LAS and decreasing the RMS in the older animals), which are most commonly found in elderly animals due to fibrofatty myocardial infiltration correlated with aging. The fact that only LAS mean values was different in age subgroups of Boxer dogs may be explained by the distribution of the animals in each subgroup, with more animals in the $>4$ to $<8$ years group than in the other groups.

Although SAECG decreases the noise level that often contaminates the electrocardiogram, excessive muscular activity in restless dogs can generate poor quality recordings. Therefore, this test can be performed with the animal sedated when necessary. Some authors have demonstrated that sedation improves the SAECG recording in dogs by adequately reducing the noise level in the baseline without altering the parameters evaluated (Kushner et al., 1996). However, in the present study we chose to perform the SAECG without the aid of sedation because of owner resistance to this procedure. As a result, several recordings that showed baseline interference due to muscle tremors and restlessness in some animals were excluded.

Although most SAECG studies in dogs have been performed with the animals in left lateral recumbence (Kushner et al., 1996; Calvert, 1998; Calvert et al., 1998a; Bernadic et al., 2005; Ferreira, Camacho, 2005), in the present study, as in other studies that analyzed the SAECG in Boxer dogs, we chose to conduct the investigation with the dogs positioned in right lateral recumbence (Kushner et al., 1996; Spier et al., 2001).

The lack of standardization in the measurement of the SAECG variables obtained in different studies is notable. Calvert et al. (1998b), assessing the SAECG in Doberman dogs with occult cardiomyopathy, considered the presence of late potentials if RMS values of the last 40 or 30 milliseconds of QRS complex (RMS40 and RMS30), as well as filtered QRS and LAS $<40$ $\mu \mathrm{V}$, were outside the reference values. Ferreira and Camacho (2005) evaluated only the RMS40, QRSd and LAS $<40 \mu \mathrm{V}$ of the SAECG of normal dogs and dogs with dilated cardiomyopathy induced by doxorubicin. Spier and Meurs (2004b), analyzing the SAECG of Boxer dogs with ARVC, considered the presence of LP with changes in at least two of the four RMS analyzed, RMS30 and RMS40, with two different types of filters ( 25 to $250 \mathrm{~Hz}$ or 40 to $250 \mathrm{~Hz}$ ). According to Calvert et al. (1998b), because the QRS duration is significantly shorter in dogs than in humans, the RMS40 of the former has the disadvantage of including a higher number of high-voltage signals. Therefore, the RMS30 is preferable as a measurement because it better covers the lowvoltage signals corresponding to the LP. Despite the recommendation of these authors, this study evaluated only the RMS40 because the decoding software used did not include the RMS analysis of the last 30 milliseconds of the QRS, allowing analysis only of the last 40 milliseconds.

The number of altered parameters required to diagnose LP in SAECG also requires standardization. In human medicine, the SAECG is abnormal when there are changes in at least two parameters analyzed using a specific type of filter (Leclercq, Coumel, 1993; Turrini et al., 1999; Steriotis et al., 2009). There are, however, differences in test interpretation in veterinary medicine. Calvert et al. (1998a) considered as abnormal (LP present) the SAECG of Doberman dogs that showed changes in all parameters studied (QRSd, LAS $\angle 40 \mu \mathrm{V}$ and RMS), while Spier and Meurs (2004b) defined the SAECG of 
Boxer dogs as abnormal when there were changes in at least two of the four types of RMS analyzed. In this study we decided to consider LP presence on SAECG with changes in at least two of the three parameters studied (QRSd, LAS $<40 \mu \mathrm{V}$ and RMS40).

The values obtained in this study can be compared to those of some studies that used similar methodology and dogs of similar size. Comparing the results obtained here with those of Calvert et al. (1998a), who performed SAECG in healthy Doberman dogs, the QRSd values considered abnormal were similar, but the LAS $<40 \mu \mathrm{V}$ and RMS40 showed some differences. Comparing these values with those obtained by Spier and Meurs (2004b), who performed SAECG in healthy dogs of various breeds (but not Boxers), the QRSd, LAS $<40 \mu \mathrm{V}$ and RMS40 values studied also showed similarity. The values obtained for QRSd and $\mathrm{LAS}<40 \mu \mathrm{V}$ in this study were also analogous to those found in a study of SAECG in normal dogs with similar weight as the dogs used in this study (Ferreira, Camacho, 2005); however, the RMS values found in this study were higher.

It is well established that middle-aged Boxer dogs are susceptible to fibrofatty infiltration of the myocardium. This susceptibility is particularly seen in dogs suffering from ARVC, a hereditary autosomal dominant disease characterized by slow cardiac conduction through the myocardium infiltrated by fibrous tissue, causing onset of fatal ventricular arrhythmias and sudden death (Folino et al., 2006; Spier et al., 2001; Harpster , 1991; Meurs et al., 1999; Meurs, 2004; Basso et al., 2004). Such slow conduction of cardiac electrical stimulation can result in the appearance of a greater number of high-frequency and lowvoltage signals in the SAECG, which are suggestive of LP; however, such signals were not found in the SAECG of Boxer dogs compared to German Shepherds in this study. Therefore, even if these studied Boxer dogs had such histological changes, they did not show LP on SAECG, which suggests that LP are not present in the early stages of this disease, when significant ventricular ectopic beats on Holter examination or clinical manifestations of such arrhythmias are not yet observed.
Several studies have demonstrated LP in the SAECG of humans with ARVC (BlomströmLundqvist et al., 1988; Blomström-Lundqvist et al., 1989; Leclercq, Coumel, 1993; Kinoshita et al., 1995; Turrini et al., 1999; Nava et al., 2000; Steriotis et al., 2009; Marcus et al., 2010), although this result has been regarded as a minor criterion in the diagnosis of the disease (Marcus et al., 2010). LP was also commonly observed in Boxer dogs with ARVC (Spier et al., 2001; Spier, Meurs, 2004b). The standard SAECG values obtained in this study for Boxer dogs can be used as a basis for evaluation in future examinations of dogs affected by this myocardial disease. These values can also be used for stratification of the risk of sudden death in these animals.

Major limitations of this study include the limited number of animals enrolled due to difficulties in achieving healthy animals of the breeds studied, the restrictions inherent to the technique because it is somewhat difficult keep the animal in lateral recumbence for a prolonged time, and the paucity of similar studies to compare results obtained in this study.

The SAECG is a very important diagnostic technique in veterinary cardiology, particularly for investigation of diseases with a high rate of sudden death. Few studies have been conducted in dogs to establish normal values for this type of examination, and there is no standardized methodology in the few papers on this subject. Future studies are needed to standardize values for the SAECG in healthy dogs of several breeds. This will allow the detection of LP in dogs with dilated or arrhythmogenic cardiomyopathies and observation of the correlation of LP with sudden death in animals affected by these myocardial diseases.

\section{CONCLUSIONS}

In this study, reference values were obtained for SAECG of German Shepherd and Boxer dogs, which will be useful for detecting LP when studying SAECG in these breeds. These highfrequency and low-amplitude signals may be identified when there are changes in two or more SAECG parameters, such as higher values of QRSd or LAS $\angle 40 \mu \mathrm{V}$, or lower values of RMS40 than those established in this study. The 25 to $250 \mathrm{~Hz}$ band-pass filter proved to be more 
sensitive in detecting low amplitude and high frequency signals than the 40 to $250 \mathrm{~Hz}$ bandpass filter.

\section{REFERENCES}

BASSO, C.; FOX, P.R.; MEURS, K.M. et al. Arrhythmogenic right ventricular cardiomyopathy causing sudden cardiac death in Boxer dogs - A new animal model of human disease. Circulation - J. Am. Heart Assoc., v.109, p.1180-1185, 2004.

BERNADIC, M.; HUBKA, P.; SLAVKOVSKY, P. et al. High resolution electrocardiography in healthy dogs: time domain parameters and comparison of the non-stationary (Wigner distribution) versus standard stationary frequency domain analysis methods. Physiol. Res., v.54, p.477-484, 2005.

BLOMSTRÖM-LUNDQVIST, C.; HIRSCH, I.; OLSSON, S.B.; EDVARDSSON, N. Quantitative analysis of the signal-averaged QRS in patients with arrhythmogenic right ventricular dysplasia. Eur. Heart J., v.9, p.301-312, 1988.

BLOMSTRÖM-LUNDQVIST, C.; OLSSON, S.B.; EDVARDSSON, N. Follow-up by repeated signalaveraged surface QRS in patients with the syndrome of arrhythmogenic right ventricular dysplasia. Eur. Heart J., v.10, suppl. D, p.54-60, 1989.

BREITHARDT, G.; CAIN, M.E.; EL-SHERIF, N. et al. Standards for analysis of ventricular late potentials using high-resolution or signal-averaged electrocardiography. A statement by a Task Force Committee of the European Society of Cardiology, the American Heart Association, and the American College of Cardiology. Circulation, v.83, p.14811488, 1991.

CALVERT, C.A. High-resolution electrocardiography. Vet. Clin. North Am. Small Anim. Pract., v.28, p.14291447, 1998.

CALVERT, C.A.; JACOBS, G.J.; KRAUS, M.; BROWN, J. Signal-averaged electrocardiograms in normal Doberman Pinschers. J. Vet. Intern. Med., v.12, p.355-364, 1998a.

CALVERT, C.A.; JACOBS, G.J.; KRAUS, M. Possible ventricular late potentials in Doberman Pinschers with occult cardiomyopathy. J. Am. Vet. Med. Assoc. v.213, p.235-239, 1998b.

CORRADO, G.; LISSONI, A.; BERETTA, S. et al. Prognostic value of electrocardiograms, ventricular late potentials, ventricular arrhythmias and left ventricular systolic dysfunction in patients with Duchenne muscular dystrophy. Am. J. Cardiol., v.89, p.838-841, 2002.
FERREIRA, W.L.; CAMACHO, A.A. Avaliação da eletrocardiografia de alta resolução em cães clinicamente normais. Braz. J. Vet. Res. Anim. Sci., v.42, p.271-275, 2005.

FOLINO, A.F.; BAUCE, B.; FRIGO, G.; NAVA, A. Long-term follow-up of the signal-averaged ECG in arrhythmogenic right ventricular cardiomyopathy: correlation with arrhythmic events and echocardiographic findings. Europace, v.8, p.423-429, 2006.

HARPSTER, N.K. Boxer cardiomyopathy - a review of the long-term benefits of antiarrhythmic therapy. Vet. Clin. North Am. Small Anim. Pract., v.21, p.9891004, 1991.

KINOSHITA, O.; FONTAINE, G.; ROSAS, F. et al. Time- and frequency-domain analyses of the signalaveraged ECG in patients with arrhythmogenic right ventricular dysplasia. Circulation, v.91, p.715-721, 1995.

KUSHNER, L.I.; CALVERT, C.A.; BOYLE, C.R. Effects of acepromazine and buprenorphine on measured indices of the signal-averaged electrocardiogram in healthy dogs. Am. J. Vet. Res., v.57, p.1511-1514, 1996.

LECLERCQ, J.F.; COUMEL, P. Late potentials in arrhythmogenic right ventricular dysplasia. Prevalence, diagnostic and prognostic values. Eur. Heart J., v.14, supplement E, p.80-83, 1993.

MARCUS, F.I.; McKENNA, W.J.; SHERRILL, D. et al. Diagnosis of arrhythmogenic right ventricular cardiomyopathy/dysplasia : proposed modification of the task force criteria. Circulation, v.121, p.15331541,2010

MEURS, K.M.; SPIER, A.W.; MILLER, M.W. et al. Familial ventricular arrhythmias in Boxers. J. Vet. Intern. Med., v.13, p.437-439, 1999.

MEURS, K.M. Boxer dog cardiomyopathy: an update. Vet. Clin. North Am. Small Anim. Pract., v.34, p.12351244, 2004.

NAVA, A.; FOLINO, A.F.; BAUCE, B. et al. Signal-averaged electrocardiogram in patients with arrhythmogenic right ventricular cardiomyopathy and ventricular arrhythmias. Eur. Heart J., v.21, p.58-65, 2000.

POLL, D.S.; MARCHLINSKI, F.E.; FALCONE, R.A. et al. Abnormal signal-averaged electrocardiograms in patients with nonischemic congestive cardiomyopathy: relationship to sustained ventricular tachyarrhythmias. Circulation, v.72, p.1308-1313, 1985. 


\section{Chamas et al.}

SPIER, A.W.; MEURS, K.M. Evaluation of spontaneous variability in the frequency of ventricular arrhythmias in Boxers with arrhythmogenic right ventricular cardiomyopathy. J. Am. Vet. Med. Assoc., v.224, p.538-541, 2004a.

SPIER, A.W.; MEURS, K.M. Use of signal-averaged electrocardiography in the evaluation of arrhythmogenic right ventricular cardiomyopathy in Boxers. J. Am. Vet. Med. Assoc., v.225, p.1050-1055, 2004b.
SPIER, A.W.; MEURS, K.M.; LINN, C.G. Signalaveraged ECG in the assessment of arrhythmogenic cardiomyopathy in Boxers. J. Vet. Intern. Med., v.15, p.307, 2001.

STERIOTIS, A.K.; BAUCE, B.; DALIENTO, L. et al. Electrocardiographic pattern in arrhythmogenic right ventricular cardiomyopathy. Am. J. Cardiol., v.103, p.1302-1308, 2009.

TURRINI, P.; ANGELINI, A.; THIENE, G. et al. Late potentials and ventricular arrhythmias in arrhythmogenic right ventricular cardiomyopathy. Am. J. Cardiol., v.83, p.1214-1219, 1999. 